\title{
How to Apply Psychology to Physical Education Teaching
}

\author{
Pinglin Lu \\ College of Physical Education, Guangxi Normal University, Guilin, 541004, China
}

\author{
Keywords: Psychology, Physical education, Quality education
}

\begin{abstract}
The related research shows that in different sports situations, people's psychological activities also is the huge differences in the environment. This kind of psychological activity and the current sports activities have a certain relationship and an anti - effect. The different kinds of sports activities can promote the psychological quality of students in sports activities besides the psychological factors of the activities. This paper has studied to apply psychology in physical education teaching, to further enhance the level of physical education, and hope to provide some theoretical support for the development of physical education.
\end{abstract}

\section{Introduction}

With the development of social science and technology, the market economy has gradually become the main feature of today's society.it is the focus and difficulty of the education sector that How to enhance the students' comprehensive quality in the teaching practice, and promote the comprehensive development of students. As an important part of quality education, physical education should be reformed in order to create the appropriate conditions for the students' comprehensive quality. In the modern society, the government attaches great importance to the quality education, with the continuous application of multimedia technology in teaching practice, the traditional sports teaching has also been affected by the Impact from all aspects, The problems in classroom teaching are exposed, which has a bad influence on the improvement of students' sports quality. The psychological theory is applied in physical education, so that the emotional education and physical education practice is organic combined, the potential of students is maximized, stimulate students to participate in sports activities, and gradually improve the shortcomings of the traditional physical education, so that students in a relaxed atmosphere to complete the task of physical education, and enhance the effectiveness of physical education.

\section{The psychological characteristics of students in the Physical Education}

The psychological characteristics of students in the physical education are many aspects: first, in sports activities, students has a very strong desire for knowledge, has the high expectations of sports, hope to grasp the relevant skills of the teachers and professors, to get excellent sports performance, to be praised by the teachers and students, etc. Secondly, in the process of physical education, students are eager to get the attention of teachers, and get the guidance of the teachers, also need the help and support of other students. In the guidance and communication of teachers, students can have a positive learning enthusiasm, gain self-esteem and self-confidence, and then inspire students to explore and explore their own potential passion, complete learning tasks, improve their sports quality; thirdly, in the teaching practice, the students have some differences in personality, which are different from the living environment and physical quality. the unified education mode Will make the relatively poor students have a greater emotional fluctuations, is not conducive to the further development of teaching activities, and even have a bad effect to the future development of the students. 


\section{The significance of integrating psychological theory into physical education}

There are some mutual influence and mutual support between psychology and physical education and neither of the two can be dispensed for ensuring the quality of teaching. In the practice of physical education teaching, appropriate using psychological knowledge is great significance. The long-term research of sports psychology found that students will build a specific sports situation in the process of sports activities, and students will have many complex psychological changes, these psychological phenomena and the development of physical education teaching activities have a certain influence from each other. As is known to all, the inner activity is influenced by a person's inner spiritual cultivation, and because of this, it is important to pay attention to the students' inner activity pattern in physical education teaching practice. It is a very important part of the students' inner demands, and it is also the foundation of the development of quality education. At this stage, the government pays attention to quality education, to build a new education model which can effectively excavate the potential of students by strengthening the students' comprehensive development ability and innovation ability. It should be recognized that in the course of the implementation of physical education, the teaching effect and quality of teaching quality are important to students' physical education quality and physical and mental health. Therefore, physical education should strengthen the emphasis on psychology education, base on the law of the students' psychological development as well as the current social mainstream development trend, to take some measures to improve students' physical and mental health level.

All in all, sports can produce a negative effect of emotions. In the process of sports, appropriate integration of psychology education can effectively reduce the psychological burden of students, have a positive impact for the future growth and development of students. Appropriate integration of psychology education is not only the basis of ensuring the smooth development of physical education, but also can provide the important reference basis for students' mental health education.

\section{To grasp the psychological characteristics of students and improve the quality of Physical Education}

\section{To Stimulate students' learning interest, to strengthen learning motivation}

Psychology research clearly pointed out that the interest have important influence on the social life and related activities, is the spiritual motive of human to acquire new knowledge in the society, broaden one's horizon. Interest is the best teacher to understanding the nature and the society. In order to stimulate students' interest in learning, to strengthen learning motivation, first of all should take some measures to promote students to develop an interest in sports activities, through teaching and guidance to promote students' interest to maintain long-term stability, and to deepen the students' understanding of the basic knowledge of physical education, so that students can correctly understand the purpose of physical education [3]. Students were different in the different stages of growth, abstract logical thinking has gradually formed, in different periods students maintained vigorous energy and creativity and strong enterprising interest, especially in sports games, it is more obvious. But, by the law of psychological development, the students' interest in physical education is not enough. Once encountered some difficulties and setbacks, students will have a shake, Therefore, in the practice of physical education, teachers should use psychology knowledge, to build a relaxed and free sports learning environment, interesting teaching content, and in the "people-oriented" education ideas, to encourage and care for each student, so that students can build the study confidence, take the whole body into physical education, strengthen learning effect. In the specific operation, the teachers should help students to make clear the purpose of physical education, to promote students to have the perseverance, perseverance and gradually realize their own life value, to strive for the ideal. For example, in the teaching of physical education theory, teachers can introduce it to students that the rise of the Chinese sports, table tennis of china, how Ma Jiajun create brilliant history etc., let students to strengthen their physical education learning beliefs, to further stimulate students interest in participating in sports activities, to promote the all-round development of students. 
Secondly, to stimulate students' interest in learning through the construction of the teaching environment, to promote students in the process of physical education to produce a strong desire for knowledge. Teachers in the classroom teaching should guide students to solve various difficulties, and use innovative teaching methods to cultivate students' ability to multi angle thinking, and ultimately the students obtain the joy of success from physical education. At the same time, the teacher's own quality has an important influence on the psychological development of students. The quality of teaching is directly influenced by the communication between teachers and students. [4]. the image of the teacher play an Important role in the Psychological quality, mental thought and behavior habit of students. If teachers is depressed mood, the students will subsequently depressed, lose interest in learning on the sports; and if teachers is high spirits, the mood of the students will become infected with the corresponding, Interest in learning, teaching activities can also carried out smoothly.

In sports teaching, teachers are in the dominant position. The teachers' teaching method is very important to students' physical education. So teachers should pay more attention to students' main position, pay attention to students' main position, make every student participate in sports activities, and promote students' learning desire and strengthen their learning effect, lays the foundation for the future development of students.

\section{To Actively reform and innovation, to overcome the teaching mode, to develop students' creative thinking ability}

The focus of teaching reform is the innovation of teaching method, which is that teachers should actively explore new teaching system, change the traditional rigid teaching ideas, and finally get the breakthrough in teaching effect [5]. For example, teachers can apply the psychological suggestion, comparative competition, model demonstration and other methods, in teaching practice, so that students produce a sense of novelty, and stimulate creative consciousness. At the same time, we should ask some questions to students, through suggestive language to inspire students to participate in sports activities, positive thinking and found the problem, and from multi angle to think and solve the problem.

For example, in basketball jump shot teaching, teachers can first demonstrate several times to students, and then let the students to analyze the teacher's action points, such as the ball position, the run-up step number, direction of take-off, wrist force etc., Then the students complete the jump according to the own summary, students are usually failure because not master all point, then teachers can carry out comprehensive and detailed explanation, this action segmentation into several steps, explain the point in every steps and carry out demonstration. Finally, Organize students to jump shot according to the second explanation, teachers carefully observe the students movement and timely pointed out the presence of problems, help students to success, experience the fun of basketball jump shot. So that the students can have a sense of achievement in the learning process, can improve the learning effect, at the same time, expand students' way of thinking, to lay the foundation for the future development of students.

\section{Pay attention to adjust the psychological state of the students, effective control all aspects of teaching}

In physical education, Students need to carry out repeated practice to eventually master the technical essentials of the action. In this process of learning, the students will have complex psychological fluctuation, Such as low quality of students' learning is slow, prone to weariness, inferiority, and better quality of the students' learning is fast, but often because the essence of proud is difficult to experience the real action. Therefore, we should pay attention to the students' psychological fluctuations, discover the problems of the students' psychology, and try to avoid the psychological barrier.

For example, in learning of the high jump, some student's psychological quality is poor, lack of confidence, fear of failure, cannot take the courage to take off at the pole. At this time, the teacher should actively encourage students and to reduce the difficulty, and suggest other students pretend to 
be fault, and enhance the confidence of students to participate in activities. In the cooperation of teachers and students, students with poor psychological quality can produce a balanced psychological, and then overcome the psychological barriers, the completion of the high jump have a positive impact for the future development of the students.

\section{Concluding remarks}

The application of psychological knowledge in physical education teaching can have a positive impact on the improvement of teaching effect. It also plays an important role in the development of students' physical and mental health. Therefore, teachers should take the corresponding measures, infiltrate psychological thoughts into physical education, through the correct grasp of the psychological characteristics of students, to choice teaching methods, to stimulate students' interest in learning, and gradually improve the teaching effect, and promote the comprehensive development of students.

\section{References}

[1] Chen Lin, Zhang Hong, Wang Xiaofeng et al. Psychological presupposition of physical education in the perspective of life education. Journal of Chengdu Sport University, 2012,38 (9): 84-87.

[2] Tang Huiqiang. The analysis of the vocational school physical education teaching based on psychology. career, 2015 (2): 99-100.

[3] Lin Weijing. The function of sports games in physical education from the perspective of Psychology. City Tutor (the second half), 2014 (7): 137-138.

[4] Teng Tonghua. The function and application of sports psychology in Physical Education. Education Teaching Forum, 2014 (23): 95-95,96.

[5] $\mathrm{Hu} \mathrm{Xi}$. On the. The function and application of sports psychology in Physical Education. Heilongjiang science and technology information, 2012 (33): 197-197. 